\title{
The Design and Application of Intelligent Buoys in Polar Water
}

\author{
Si-wen Guo ${ }^{1, a}$, Yuan-zhou Zheng ${ }^{1,2, b}$, Lang-xiong Gan ${ }^{1,2, c}$ \\ Chun-hui Zhou ${ }^{1,2, d}$, Cai-yun $\mathrm{Xu}^{1, \mathrm{e}}$ \\ ${ }^{1}$ School of Navigation, Wuhan University of Technology. Wuhan, Hubei, China \\ ${ }^{2}$ Hubei Key Laboratory of Inland Navigation Technology. Wuhan, Hubei, China \\ a904843462@qq.com, bhengyuanzhou0909@163.com, ${ }^{\mathrm{c} g} \mathrm{glx} 701227 @ 163 . c o m$, \\ d24003482@qq.com, ${ }^{\mathrm{e}} 793401950 @ q q . c o m$
}

\begin{abstract}
Keywords: Intelligent Buoy; Wind-solar Hybrid; Self-insulation Battery Management Module; Beidou Satellite

Abstract. In order to solve the problem of insufficient energy supply for buoys in polar waters, a wind energy / solar energy composite energy collection device was designed which can make full use of wind energy. What's more, the lithium battery module of traditional buoys was improved, and a self-insulation battery management module was designed. Finally, after the implementation of the technology, the application of Beidou satellite can provide information for controllers more accurately and quickly.
\end{abstract}

\section{Introduction}

Polar waters in high latitudes are with low temperatures, large waves and abundant wind energy. The buoy is a kind of navigation aids and it can mark the direction of the waterway, boundaries and obstruction of the signs. It is an artificial sign that helps guide the vessel in navigating, locating and marking the obstruction. Polar regions have vast waters and require buoys during the operation of ships. However, most of the traditional buoys are powered by solar energy, and the performance of the traditional lithium battery is reduced under low temperature conditions, which will lead to the abnormal use of the buoys. Therefore, a solar wind power system can be designed to provide power and it is of vital significance to design a battery warming system to ensure the normal operation of buoys.

In positioning communication, "GSM + GPS" mode is used in traditional buoys. The communication mode of GPS system is unidirectional, so it also needs to send and receive information through the bidirectional communication function of GSM module. Although the structure of this system is not complicated, taking into account the more extensive polar waters, GSM signals have not yet been fully covered in some areas, so the buoys in the blind area of this type of operation cannot be monitored [1]. Compared with GPS, Beidou satellite can provide short message communication service. Buoys can directly transmit information to the control center to provide managers with the information delivered by the navigation aids more accurately and quickly.

\section{Introduction of Polar Waters}

Polar waters refer to the water areas in the earth's Antarctic Circle and the Arctic Circle. The Arctic waters, centered on the Arctic Ocean, are surrounded by the three continents of Asia, Europe and North America. Antarctic waters, centered around Antarctica, are surrounded by the Pacific Ocean, the Atlantic Ocean and the Indian Ocean.

The temperature of the polar areas is low all the year round. Winters in Arctic Ocean last 6 months, from November to the next April. The average temperature in January ranged from -20 to $-40{ }^{\circ} \mathrm{C}$. August is the warmest month, and the average temperature only reaches $-8{ }^{\circ} \mathrm{C}$. The lowest temperature found on the drifting station near the poles of the Arctic Ocean is $-59^{\circ} \mathrm{C}$. Compared to the Arctic, the Antarctic is colder. Antarctica is the coldest place in the world. The average temperature near the South Pole is $-49^{\circ} \mathrm{C}$ and in the cold season it is $-80^{\circ} \mathrm{C}$. Antarctica is not divided into four seasons. It only has the warm season and the cold season. The warm season ranges from November to 
March, and the monthly average temperature is between $-34^{\circ} \mathrm{C}$ and $-20^{\circ} \mathrm{C}$. As for the cold season from April to October each year, the temperature is generally between $-40^{\circ} \mathrm{C}$ and $-70{ }^{\circ} \mathrm{C}$.

In addition to low temperature, polar waters have larger waves and storm. Take Antarctica as an example. Antarctica is the coldest place in the world, and it also has the most wind-power. There are 300 days with an average of more than 8 graces per year, with an average annual wind speed of $19.4 \mathrm{~m}$ / s. The maximum wind speed observed at the Mauser Station in Australia in 1972 was $82 \mathrm{~m} / \mathrm{s}$. At Devereux Station in France, the hurricane with speed of $100 \mathrm{~m} / \mathrm{s}$ has been observed, which is equivalent to three times of a 12-level typhoon and it is the largest recorded wind speed in the world. Thus, the polar waters have sufficient wind energy, and the wind energy can be used in power generation.

\section{The Design of Composite Energy Collection Device}

Advantages of Wind and Solar Hybrid Energy. At present, buoys are mainly powered by solar energy. However, the storm and waves are larger in polar waters, and the weather is more serious. What's more, due to the high latitude, there happens polar day and night. This shows that solar energy cannot be sustained for the buoys, which will affect the normal work of the buoys. Polar waters have rich wind energy. Therefore, both solar energy and wind energy can be used to charge the buoys.

Solar energy and wind energy are the most widely distributed and most efficient renewable energy sources. But there is a strong uncertainty due to the seasons, geography, climate and other factors. However, both of them have certain complementarity in terms of time and geography. At the same time, they can be shared between energy storage and inverter. They are suitable for combined power generation and resource complementarity, and can improve the reliability of system power supply [2]. Compared with independent photovoltaic or wind power system, wind and solar power generation system can obtain more stable power output, improve equipment utilization and reduce system cost, and can reduce the configuration capacity of energy storage equipment under the same power supply [3]

The Design of Vertical Axis Wind Power Generation Module. Wind-solar hybrid power supply modules are mainly composed of wind power generators, solar photovoltaic cells, controllers, batteries, inverters, and AC and DC loads [4]. The wind power generator module is mainly composed of a wind turbine module and a generator module. The former uses a wind wheel to capture and absorb wind energy and converts it into mechanical energy to the latter, and the latter converts the mechanical energy transmitted by the former into electrical energy [5]. Wind turbine is a kind of device which can convert wind energy into other forms of energy. Wind turbines are divided into two types: vertical axis wind turbine and horizontal axis wind turbine. The feature of the horizontal axis wind turbine is that the direction of the rotation axis of the wind wheel is consistent with the direction of the wind, and it is widely used. The feature of the vertical axis wind turbine is that the rotation axis of the wind wheel is perpendicular to the ground or the wind direction, and the vertical type wind turbine has the outstanding advantage that the wind energy in any direction can be captured without the need of a wind device. Therefore, in order to better collect the wind energy in all directions and improve the working efficiency of wind turbines, this paper uses a vertical axis wind turbine, as shown in Figure 1. 


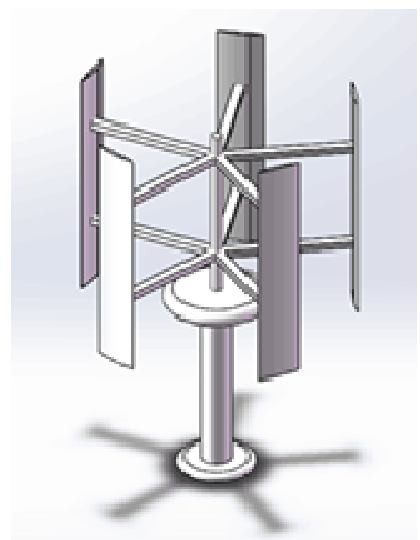

Fig.1 Vertical Axis Wind Turbine

The Design of Solar Power Module. To make better use of solar energy when chasing solar installations and increase power generation efficiency, the direction of the solar cell can be adjusted to make the rotating axial solar panel located in the north and South and perpendicular to the trajectory of the sun. In this way, solar panels in the north-south axis can be adjusted according to the change of the solar elevation angle to perform east-west rotation to maximize the power generation efficiency, simplify the mechanical structure, and reduce the motor load.

The solar power module is shown as Figure 2. The light intensity detection module is composed of eight light intensity sensors equipped with BH1750FVI chip uniformly distributed in the $180^{\circ}$ sector from east to west. Eight light intensity sensors are connected with the analysis control module with the STC89C52 microcontroller through the IIC, and can be connected through the 16bitA / D converter. It will measure the light intensity directly into the Lux (illumination unit) as a unit of digital sent to the microcontroller for single-chip analysis. First, the STC89C52 microcontroller through the IIC bus has been received and stored on the 8 sensors to collect light intensity data, and then call the internal settings of a comparative analysis of the algorithm to calculate the maximum intensity point elevation, Finally, the output signal of PWM is used to control the mechanical transmission module driven by L298N driver chip and drive the stepper motor to drive the solar panel accurately to the elevation angle where the maximum intensity of light is located, so as to achieve the maximum power generation efficiency.

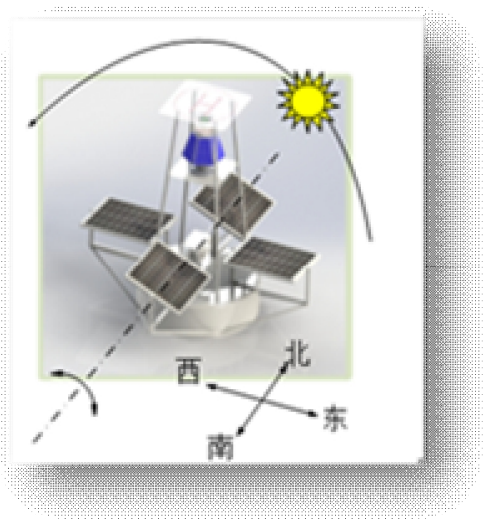

Fig.2 Design of Solar Power Module

\section{The Design of Self-heating Battery Management Module}

At present, buoys are generally powered by lead-acid batteries and use solar energy to charge lead-acid batteries, which usually cannot maintain long working hours. In addition, there is a large temperature difference between day and night at sea, especially in the polar regions where the temperature is low throughout the year. In order for the buoy to work properly, it is necessary to use a battery cell to form a battery pack by series-parallel connection. Besides, a self-heating battery management module is 
designed so that it can regulate the temperature field inside the battery pack, and the temperature of the battery pack is controlled within a reasonable range.

Battery thermal management module shown in Figure 3. The heat management module of the battery is an aluminum sheet embedded with a PTC board. PTC is a kind of heating material with high heat transfer efficiency after power on, which can make the battery pack rapidly heat up in a short period of time and prevent the temperature from rising excessively after reaching a certain temperature. The main function of the thermal sheet is reflected in two aspects: on the one hand, the heat generated inside the battery is conducted to the surface of the battery, and the heat is dissipated through the aluminum sheet to balance the temperature between the single cells. On the other hand, the heat generated by the PTC is uniformly transmitted to the battery cells through the aluminum plate at a low temperature.

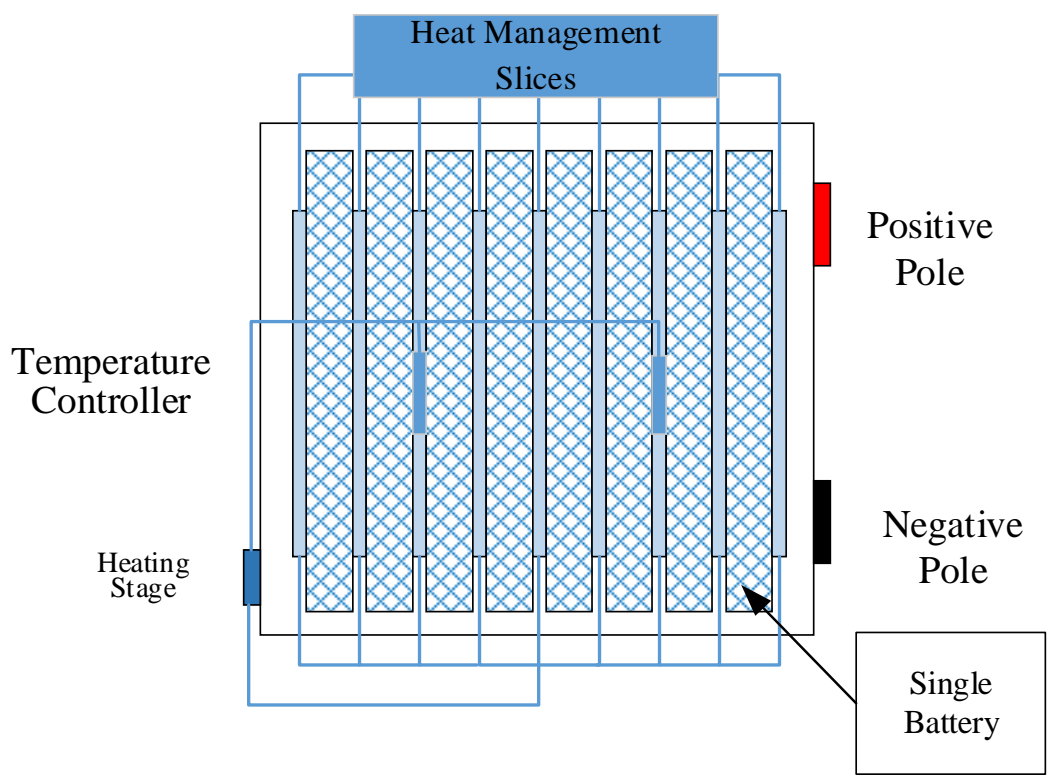

Fig.3 Battery Heat Management Diagram

By using the battery heat management system, the lithium battery can always be kept at the right temperature. At the same time, the dormancy mode of the terminal is taken to make the terminal of the buoy work intermittently, and the power consumption of the system can be reduced. Dormant work flow is shown in Figure 4.

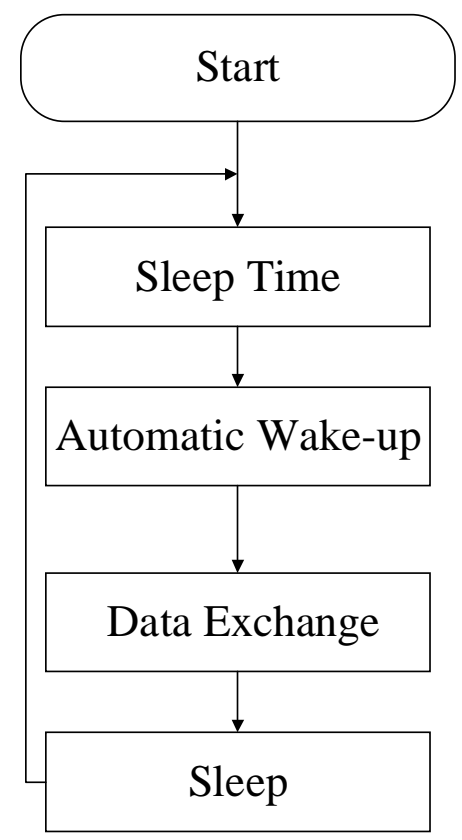

Fig.4 Sleep Mode 


\section{The Application of The Beidou Satellite in the Intelligent Buoys}

The Introduction of Beidou Satellite. Beidou Navigation Satellite System, BDS, is a global satellite navigation system developed by China. BDS is the third mature satellite navigation system in the world after the United States Global Positioning System (GPS), the Russian GLONASS Satellite Navigation System (GLONASS). BDS, GPS, GLONASS and GALILEO (Galileo satellite navigation system) are the suppliers identified by the United Nations Satellite Navigation Commission. The Beidou satellite can not only provide passive location services with other orbiting satellites, but also provide active location, location reporting and short message communication services to the regional users from these 5 GEO satellites. Beidou short message communication outbound channel rate is $31.25 \mathrm{kbps}$, inbound channel rate is $15.625 \mathrm{kpbs}$, a maximum of 200 bytes of data can be widely used in public network signal coverage and emergency rescue and other fields [6].

The Application of Beidou Satellite in Intelligent Buoys. At present, the Beidou satellite system has covered China, Taiwan, South China Sea and other islands and reefs, China's territorial waters, the Japan Sea, parts of the Pacific Ocean, and parts of the surrounding area [7]. Beidou Satellite will form an autonomous, technologically advanced, stable and reliable navigation system in 2020 which can cover the whole world. The intelligent navigation system using Beidou satellite has complex system functions, involving various technologies such as network and system management, server systems, data storage systems, application software, and automatic detection and control. The use of Beidou satellite intelligent buoy is shown in Figure 5 [8].

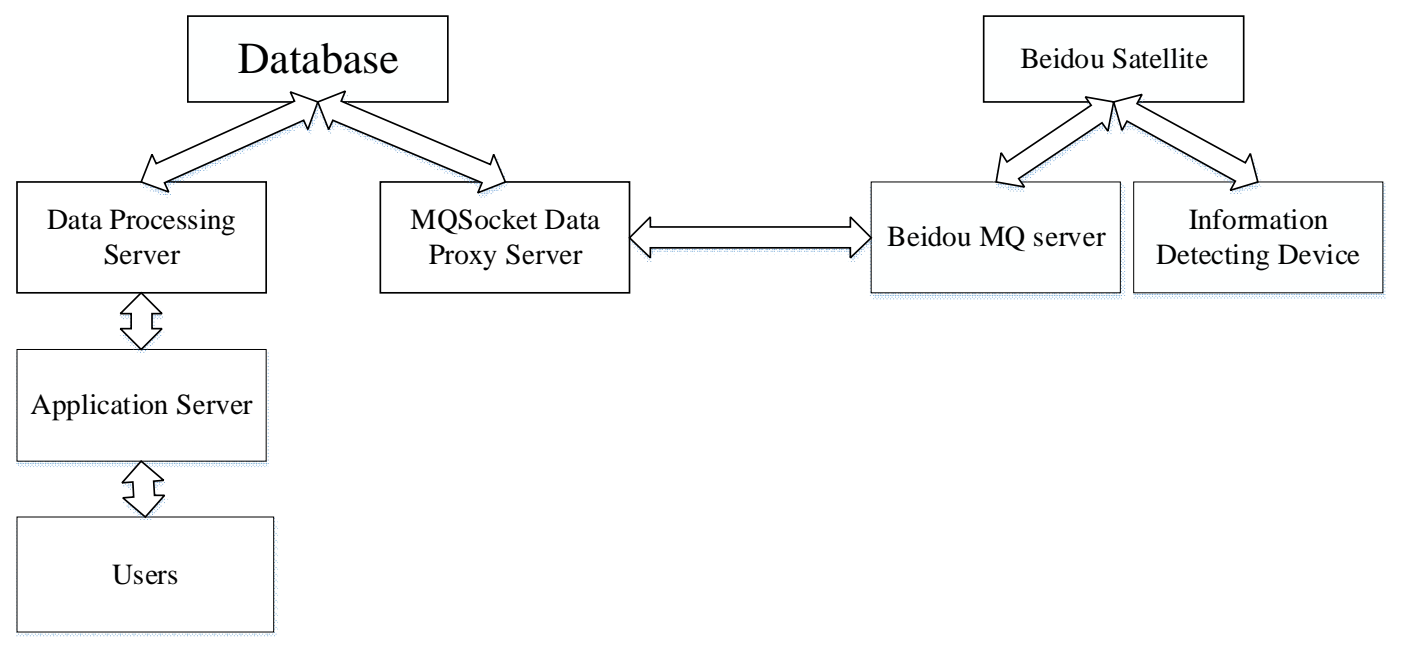

Fig.5 The Structure of the Beacon Control System Based on the Beidou Satellite

Beidou satellite communication system consists of information monitoring platform and telemetry remote terminal. The information detecting device installed on the terminal can detect the working status of the buoy light, and sends the collected terminal data and the instruction execution result package to the Beidou satellite network through the Beidou satellite communication module, and the data is forwarded by the network to the Beidou MQ server. The Beidou MQ server decodes the information and sends the data to the MQSocket data proxy server. After filtering the information, the data is stored in the database. The data processing server periodically detects the returned information of the received buoy terminal, and processes the data effectively, then stores the data in the database to supply the integration with the server call, and display the final result to the users. The user can also send telemetry data to the designated buoy terminal through the web interface provided by the application server. The instruction is stored in the database after the data processing server is filtered, and the MQSocket data proxy server monitors the data to be sent in the database in real time. After discovering the new instructions, the MQSocket data proxy server repackages the telemetry and remote control data and sends it to the Beidou MQ server through the designated port. The Beidou MQ server forwards the information to the Beidou satellite communication network. After the data reaches the navigation terminal, the buoy terminal decodes and executes relevant instructions. 


\section{Summary}

In view of coldness and the shortage of sunlight in the polar regions, wind and solar hybrid energy and self-insulation battery management module can be modified in the existing intelligent buoys. It can make full use of wind and solar energy, ensure the work efficiency of the buoy, and save energy and environmental protection. With the continuous development of modern communication technology, the Beidou satellite navigation system will be a powerful driving force to promote the upgrading intelligent buoys. It is of vital significance for us to make full use of the new technology to improve the overall level of the information system of the buoys.

\section{References}

[1]L.S.Huang: The Research of Navigation Mark Monitoring System in WuHan Harbor Based on BEIDOU System(Wuhan University of Technology,2006).

[2] L.L.Zhuang: Characteristic Analysis and Control Strategy of Wind-solar Complementary Power Supply System( Shandong University,2017).

[3] M.R.Zhang, C.X.Cheng: Modeling and Simulation of Grid-Connected Wind/PV Hybrid Generation System (Power System and Clean Energy, 2014).

[4] X.Q.Li, Q.P.Wen: Analysis of China's Wind Energy and Solar Energy Complementary Power Generation System(Modern Economic Information, 2012).

[5] X.Z.Liu, Y.L.Zhao: Introduction of National Wind Energy and Solar Energy Storage and Transmission Demonstration Project and Analysis of Its Typical Operating Mode (China Computer \& Communication, 2016).

[6] J.Y.Liu: Status and Development of the Beidou Navigation Satellite System(Journal of Telemetry, Tracking and Command, 2013).

[7] J.D.Zhao. The Application the Beidou Satellite Navigation Technology in the Information System of Navigation Mark( Maritime Technology).

[8] Y.L.Lyu and J.Wang: Application of Beidou Navigation Satellite in Navigational Aid Telemetering and Telecontrol System(Science \& Technology of Ports, 2016). 